\title{
Beckett: la música de la indiferencia
}

\author{
SERGIO CUETO Universidad Nacional de Rosario, Argentina / sergiojcueto@hotmail.com
}

\section{Resumen}

A partir del análisis de un poema de Beckett, se intenta caracterizar no sólo su concepción de la música sino la música que escuchamos en su obra. Para ello será preciso articular la cuestión de la voz con los motivos del silencio y el murmullo, el dolor y el desierto. De ese modo, entendemos, se podrá caracterizar a la «música de la indiferencia» como una música sin progreso ni resolución, sin identidad ni interioridad, sólo igual a su propia desigualdad —indiferente, como dice el poema.

Palabras clave: Beckett / música / literatura / desierto / indiferencia

\section{The music of indifference}

\section{Abstract}

Analyzing a Beckett's poem, we will try to characterize not only his music conception but also the music we listen in his work. To accomplish this, it will be required to articulate the question of the voice with the motives of silence and murmuring, pain and desert. Therefore, it will be possible to characterize the "music of the indifference» as a music without progress or resolution, without identity or interiority, only equal to his own unlikeness —indifferent, as the poem says.

Key words: Beckett / music / literature / desert / indifference

Fecha de recepción: 19/08/2017; fecha de aceptación: 11/12/2017

Para citar este artículo: Cueto, Sergio (2018). «Beckett: la música de la indiferencia». El taco en la brea 7 (diciembre-mayo), 15-21 Santa Fe, Argentina: UNL. DOI: https://doi.org/10.14409/tb.voi7.7351 
Entre los 12 poemas que Beckett escribió, en francés, entre 1937 y 1939, hay uno sin título que recordamos particularmente por su primer verso, «música de la indiferencia», y que leeremos con la esperanza, vana de entender algo, un poco, de lo que dice o habrá tenido para decir de la música. Es la traducción de Jenaro Talens:

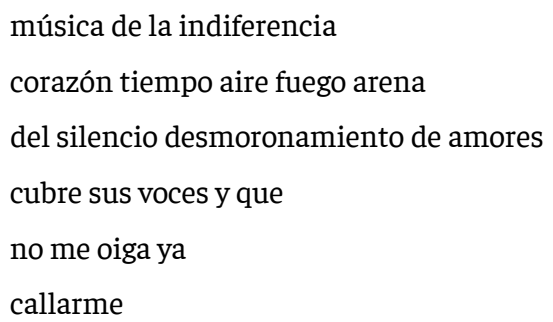

El poema es un apóstrofe. La voz se dirige a la música, acude a ella, o más bien la llama, le suplica que venga, que llegue, a ella que ya está ahí, puesto que al alcance de la voz, y que no está ahí todavía, puesto que es preciso llamarla, hacerla venir, que está ahí y que no está ahí, entonces, quizá sencillamente porque es la música, que viene antes de haber llegado y sólo llega después de haber partido. Se objetará que para tratarse estrictamente de un apóstrofe la súplica, la invocación o la evocación de la voz, debería interrumpir un discurso anterior, mientras que aquí está en posición inicial, en el comienzo mismo del poema. Y sin embargo es efectivamente eso lo que sucede. La evocación tiene lugar en medio de lo que la voz llama el callar. Callar es tal vez hacer silencio, pero como tal es un hacer elocuente, es la elocuencia vociferante del que no puede o no quiere o no tiene nada para decir. Callar es no decir, pero un no decir que es la mera inversión del decir, decir inverso en el que el decir se oye como negatividad sin fin. El problema con el callar es que callar no es meramente callar. Siempre se calla ante algo (en el poema se trata de esas voces por ahora desconocidas con las que se desmorona el silencio), y de modo que ese algo llena, abruma, infecta el callar; y siempre calla alguien, no hay callar que no suponga un sujeto, aunque más no sea aquél al que se escucha y que se escucha a sí mismo callar. De manera que, en definitiva, el callar no calla, se oye todavía más alto que todas esas voces que atormentan al sujeto y a las que sin embargo tampoco puede acallar, parece. Es ese callar el que el apóstrofe del poema viene a interrumpir, o al menos en medio del que irrumpe como para implorar otra cosa. Pero de ningún modo se dirá que con ello el callar acaba. El poema ni siquiera supone tal posibilidad. Está por empezar descartado que baste con hablar para que el callar cese. De hecho el poema habla, y parece que habla precisamente de aquello ante lo que dice callar, y sin embargo su habla tiene el estatuto del mutismo, lo que en ella oye el mismo que la pronuncia es el invencible callar de la palabra. Por otra parte, el sujeto no se engaña al respecto. Lo que en su plegaria pide no es, estrictamente, que el callar cese, como si ello estuviese más allá de toda súplica, sino que uno ya no lo escuche, que uno ya no se escuche callar. Es cierto que con ello tal vez el callar deje de serlo, se convierta en un callar inaudito al que apenas si le convenga ese nombre, callar sin sujeto ni objeto, sin quién ni ante qué, pero tal cosa no puede más que suponerse.

Ahora bien, ¿qué voces son ésas ante las que el sujeto calla, no puede, parece, sino callar? El poema las nombra diciendo: corazón tiempo aire fuego arena desmoronamiento de amores. Es un conjunto heterogéneo, seguramente. Un órgano del cuerpo, pero considerado simbólicamente sede de los sentimientos y etimológicamente de la memoria; un incorporal, es decir, un no-ser o 
un casi-ser, un «algo» que no se cuenta entre las cosas mundanas; dos elementos, esto es, dos principios constitutivos de todos los seres pero que, en su pureza material, en su carácter de modos de la materia, apenas si pueden llamarse seres ellos mismos; una cosa, también, pero que no es más que el deterioro y la disgregación de otra, y que simboliza el paso del ser a la nada o de la nada a la nada, el mero pasar; y por último un sentimiento, más bien la experiencia o el conjunto de experiencias de un sentimiento, o mejor, más precisamente, el derrumbe, el acabamiento seguramente indefinido de los encuentros y los lazos que ese sentimiento supone o simplemente designa. Se observará sin embargo que la dicha heterogeneidad dispersa, es decir, recoge en su dispersión, una multiplicidad de series que resuenan unas en las otras. El corazón recuerda los amores perdidos, se extiende hasta aquel pasado que no volverá pero nunca dejará de pasar, como pasa la arena, como se amontona la arena que pasa, y se encoge asimismo en el presente sin paso de su dolor, convertido en pura materia de dolor, de un dolor inasible como el aire y constante como el fuego, bajo el que el sujeto se desmorona como un montoncito de arena. La palabra que Talens traduce como «desmoronamiento» es «éboulement», «éboulement d'amours», dice Beckett. «Éboulement» significa, seguramente, derrumbe, deslizamiento, aun hundimiento de un terreno. Pero el sustantivo procede del verbo «ébouler», que quiere decir destripar, arrancar las entrañas. Éboulement es el desgarramiento, en todo caso el desmoronamiento que sigue al desgarramiento, el desmoronarse de lo desgarrado. El que está desgarrado ya no se sostiene, deja caer los brazos o se derrumba en una silla, casi con la misma inapariencia que la arena en el reloj. La arena alude al tiempo, que pasa sin pasar, que se amontona paso a paso sin fin en el recuerdo; pero alude también al residuo, a la materia última, a lo que queda de materia después del fin de la materia, del desgarramiento indefinido del fin. Y alude asimismo al ruido del desmoronamiento. No hay que olvidar que corazón tiempo aire fuego arena si bien son voces, las voces que la música está llamada a cubrir, son también, y precisamente en tanto voces, modalizadores del silencio, «du silence», dice el poema. La arena dice el ruido que hacen las voces del silencio. En tal sentido no permite que olvidemos otra serie ciertamente inolvidable, la serie que intenta articular el ruido de todas las voces muertas, las voces de después del fin, del desmoronamiento de la voz. Todas esas voces muertas, se dice, hacen un ruido como de hojas, de plumas, de arena, de cenizas, de hojas. Es la voz de lo que queda, voz del residuo que es un residuo de voz. Voz necesariamente plural, porque es la voz desgarrada, dispersa, sin unidad ni cohesión, del desgarramiento. Voces, entonces, voces que hablan todas juntas, cada una para sí, sin relación, sin llegar a hablar verdaderamente, a decir algo, formar una frase, pronunciar una palabra, que sólo murmuran, susurran, cuchichean. «Murmullo desgarrado", dice Beckett en otro poema, mostrando que de ningún modo las voces dicen el desgarramiento sino que el desgarramiento está en ellas, que ellas son la voz del desgarramiento sin voz. Muchos motivos se anudan o se dispersan aquí. En primer lugar hay que decir, sin temor al patetismo, que el desgarramiento es el nombre inequívoco del dolor. Ahora bien, como ya se ha observado, Michel Schneider lo ha hecho suficientemente, el dolor no es el sufrimiento. El sufrimiento es mío, habla de mí y me devuelve a mí mismo, me confirma como yo, aunque sólo sea como un yo sufriente, y me hace hablar de él, es decir, de mí, hasta complacerme en ello. El dolor, en cambio, es impersonal e inexpresivo, no sólo no es posible decirlo, decir nada de él sino que hace enmudecer al que lo padece, pues tampoco se padece en primera persona, no se trata de mí en él, no me pertenece ni me pertenecerá nunca, al contrario, me separa de mí, él, que está separado de sí mismo, sin relación con él mismo, que es la separación en sí, lo que se llama el desgarramiento, 
precisamente. Por eso no me permite refugiarme en él de mí o en mí de él, como el sufrimiento, sino que me abandona como su resto, su residuo ineliminable, la intemperie sin refugio ni reposo, el desierto. La figura del desierto reúne todos los rasgos que venimos considerando. El desierto es el lugar del abandono no tanto porque allí se abandone a la gente sino porque es un lugar sin relación consigo, desasido de sí mismo. El desierto dice la continuidad de la discontinuidad, una continua discontinuidad. Todo fluye, o más bien, todo deriva en el desierto, pero no pasa, porque el desierto es la deriva. Por eso el desierto se extiende a lo lejos, cada vez más lejos de sí, pero amontonándose, es decir, haciéndose cada vez tan intenso como sea posible, alcanzando a cada paso el extremo de su desértica intensidad. Aquél que habla, es decir, aquél que calla en el poema, aquél que en el poema se escucha escuchar las voces del silencio del desierto, no está en sentido estricto abandonado en el desierto porque él mismo se ha convertido en desierto para sí mismo. No es el desierto el que deviene sujeto, según una tradición que bien podría llamarse romántica; es el sujeto el que ha desertado de sí en el desgarramiento del dolor. El primer signo de esa deserción es el enmudecimiento. El sujeto está sin palabra en el dolor. Si pudiera decir algo, no sería el dolor, y si fuera el dolor, aunque tal cosa es imposible, no podría esperar que se lo entienda. El dolor es mudo y el mutismo es la prueba del dolor. Sin embargo el silencio del desierto tiene voz, voces, esa voz plural que se llama el murmullo, el desgarrado murmullo de arena del dolor. En tal sentido se puede entender lo que dice Ritvo hablando, creo recordar, de Beckett: a un sujeto sin lenguaje, es decir, a un sujeto absolutamente desubjetivado, le corresponde un lenguaje sin subjetividad. En otros términos: al sujeto mudo del dolor le corresponde el murmullo neutro del desierto. Se entiende hasta qué punto lo que se llama callar es una respuesta insuficiente a la experiencia desértica del poema, siempre que se entienda el callar como el acto intencional de una consciencia. Callar es callar ante la imposibilidad de hablar, pero es todavía una posibilidad del habla, es la posibilidad para el habla de retirarse, de retraerse en sí misma ante el silencio. La prueba está en que el sujeto se escucha callar, no escucha nada más, no escucha en primer lugar el desmoronarse del desierto, el desgarramiento del dolor, el murmullo del silencio, eso que sin embargo no puede no escuchar. A menos que callar quiera decir otra cosa. «Escuchar bien, a eso llamo callarme», dice por ahí el innombrable. Quizá el callar no sea un medio para la escucha sino su testimonio, su prueba para siempre improbable. Pero entonces callar ya no se escucha, no se escucha a sí mismo, pero es él la escucha, es él las voces, todas las voces que hablando para sí mismas y para nadie resuenan en él, hablan en él, sin decir nada, murmurando el silencio, llorando en silencio el murmullo, sin reflexión, ese silencio que subyace a todo, se escucha en todo, lo que Beckett llama la música última del dolor. Hacer oír el dolor silencioso, tanto más íntimo cuanto que no es mío ni de nadie en particular, es la tarea de la música. De allí la invocación del poema. El poema suplica a la música, sólo a la música puede suplicarle, que cubra («couvre») las voces del silencio. Pero entonces cubrir no quiere decir acallar. Ciertamente, puede que uno, harto de tanto sufrir en silencio, encienda la radio. Pero no es lo que dice el poema. El poema suplica a la música que guarde y abrigue en ella el desierto de silencio del dolor, es decir, se exponga ella misma como la música del desierto. Se dirá que ello no es necesario, pues ya escuchamos el desierto de voces en el poema, o bien que es imposible, pues no se puede oír el silencio. Pero lo que sucede es que la música viene ya en la invocación del poema, viene en el poema como lo que se llama ritmo y sintaxis, pero viene sin llegar, como la promesa o la espera de ella misma. No sabríamos que no podemos escuchar el dolor si no escucháramos esa imposibilidad en la música del poema. 
Ahora bien, ¿qué música es ésta? Es la "música de la indiferencia», dice el poema. ¿Qué quiere decir? ¿Qué es la indiferencia? En primer lugar, la indiferencia es la indiferencia del dolor. No la indiferencia ante el dolor (la ataraxia o la apatía), sino la indiferencia del dolor mismo, la continuidad desolada del dolor. La música de la indiferencia es un arte del desierto. Ello quiere decir ante todo que es una música de la destrucción, o que es la destrucción como música, una música hecha de escombros, que se precipita en el vacío como un montón de escombros. Por tanto una música que no recoge el tiempo sino que se dispersa en él, y si recuerda a un cristal es a un cristal hecho trizas. Una música, entonces, sin progreso, sin suspenso ni tensión, sin resolución, hecha de una especie de disolución indefinida, sin clausura, y por eso sin interior, música que se confunde con su propia negación, ya sea el ruido o el silencio, música que tiene al olvido como única memoria, y por ello sin identidad, sólo igual a su propia desigualdad, neutra, como se ha dicho, indiferente, como dice el poema. La indiferencia no es lo contrario de la diferencia. La indiferencia es todavía la indiferencia entre diferencia e indiferencia. Y sin embargo no por ello tal que se confunda con un fondo indiferenciado, lo que míticamente se llama el caos. Porque es música, y la música es forma, ella es la forma del dolor. Si aceptamos definir al dolor como el ahí del desgarramiento, como el desgarramiento mismo en cuanto junta y mantiene junto lo desgarrado, es decir, como la juntura desgarradora, lo que se llamó la diferencia, entonces la indiferencia de la música es la afirmación sin énfasis, sin acento, ya que no distingue entre lo acentuado y lo no acentuado, de la diferencia, es decir, del dolor. El dolor no está ausente de la música de la indiferencia, al contrario, es constitutivo de ella, es en ella un desgarramiento continuo y hace de ella una continuidad desgarrada, la continuidad del desgarramiento. La continuidad del desgarramiento, lo que se llama el desierto, es una continuidad sin constancia, una continuidad de interrupción. La música de la indiferencia se interrumpe continuamente, hace imposible cualquier desarrollo y se repite sin desarrollarse. Lo que parece definirla es un cierto ostinato, pero un ostinato que sin embargo coincide con la variación perpetua, es decir, no la repetición de lo mismo, no la alternancia de lo mismo y lo otro, sino la sucesión de mismos que son siempre otros. Ahora bien, esta es definición, una definición al menos, de lo que se llama el ritmo. La música de la indiferencia le da un ritmo al desierto. En ella lo mismo es una función o un efecto de lo otro, pero lo otro nunca es distinto de él, él es lo mismo en cuanto lo mismo está siempre afuera de sí y falta a su propia identidad. El ritmo instituye la separación de sí como relación consigo. Por el ritmo la ausencia de relación se torna relación. Diremos que esta relación de no-relación define el lugar de lo que se llama el sí mismo, en la medida en que el sí mismo es nada más que ese lugar. Por eso ha podido decirse que toda alma es un nudo rítmico. El ritmo es precisamente la juntura del desgarramiento. Por eso lo que lo define es el intersticio, el intervalo, la cesura, lo que también se llama la pausa. La pausa es el principio del ritmo, es el ritmo mismo. Es esta pausa que es el ritmo lo que hace del desierto una música, la música de la indiferencia. En esa pausa el silencioso derrumbe y la dispersión silenciosa del desierto se escuchan como tales. Pero por eso la pausa no es en modo alguno una pausa en la música, o al menos no en primer lugar, sino que la música es en esencia pausa. De allí, digámoslo siquiera al pasar, el desasosegado sosiego de esa música. Es ahí, en la pausa de la música, que el sujeto destruido encuentra finalmente un lugar para sí mismo. Belacqua, el personaje que Beckett halló en Dante, decía que quería vivir «en una pausa de Beethoven». En esa pausa el «sujeto», un sujeto que ya no es tal, que todavía no es tal ni lo será jamás, vuelve a sí como aquél que se pierde o se olvida de sí, vuelve al olvido de sí mismo, es decir, escucha. Por eso ha podido decirse que la música es la ausencia a sí como relación consigo, según la estructura misma de la subjetividad. 
No es de extrañar que Genette haya explicado casi con esas mismas palabras la inmediata presencia del olvido y la indiferencia en La educación sentimental de Flaubert, una obra que, dice Genette, permanece como ausente de sí misma. Esa ausencia procede de lo que hay que llamar la música de Flaubert. Flaubert libera a la novela de la escoria de la anécdota, es el primero en poner en música la historia. Todo en la novela, la novela toda tiene lugar en el intervalo, pero el intervalo es el desierto. Proust, Zola, James, Hauser, Lukács, Poulet, Genette, Rancière lo han mostrado, cada uno a su modo. No podemos detenernos en ello. Citemos tan sólo la sugerencia de Ritvo, que habría que proseguir largamente: «Quizá de esto se trate: oír a Beckett en los intervalos de la impecable frase de Flaubert, oír el cansancio, el murmullo de su voz que se deshace antes de llegar a la boca».

En la música de Flaubert escuchamos el contrapunto entre el rapsódico ajetreo vacío de las acciones y las pasiones cotidianas que expresa la renovada voluntad de vivir y el bajo continuo del tedio en el que la duración pura se confunde con la pura quietud. Así, por ejemplo:

Viajó.

Conoció la melancolía de los paquebotes, los fríos despertares bajo las carpas, el aturdimiento de los paisajes y de las ruinas, la amargura de las simpatías interrumpidas.

Volvió.

Frecuentó el mundo y tuvo otros amores. Pero el recuerdo continuo del primero los volvía insípidos; y además la vehemencia del deseo, la flor misma de la sensación se había perdido. Sus ambiciones intelectuales también habían disminuido. Pasaron los años; y soportaba el ocio de su inteligencia y la inercia de su corazón.

En Beckett la melodía flaubertiana naufraga y se hunde en el continuo del desierto, el murmullo desgarrado de la arena; de ella sólo quedan algunas notas sueltas, generalmente en la forma del recuerdo, que acá y allá, de vez en cuando, puntúan el silencio. Pero el silencio es ya la voz que lo dice, no lo dice, no puede decirlo, no puede callarlo, y por eso se desdice sin fin, no es el silencio ni el habla, es la indiferencia entre el habla y el silencio, la música de la indiferencia. Así, por ejemplo, esto, de Textos para nada:

no está, el corazón no está, la cabeza no está, nadie siente nada, nada pregunta, nada busca, nada dice, nada oye, es el silencio. No es cierto, sí, es cierto, es cierto y no es cierto, es el silencio y no es el silencio, nadie hay y alguien hay, nada niega nada. Y la voz, la vieja voz desfalleciente, se callará por fin que no será cierto, como no es cierto que hable, no puede hablar, no puede callar. Y habrá un día aquí, donde no hay días, aquí que no es un lugar, originado por la imposible voz el infactible ser, y un comienzo de día, en que todo será silencioso y vacío y oscuridad, como ahora, como pronto cuando todo haya acabado, cuando todo esté dicho, dice ella, murmura.

\section{Bibliografía}

Beckett, Samuel (2002). Obra poética completa. Madrid: Hiperión. Traducción de Jenaro Talens. (2003). Relatos. Barcelona: Tusquets. Traducciones de Félix de Azúa, Ana María Moix y Jenaro Talens. 
Flaubert, Gustave (1977). La educación sentimental. Buenos Aires: Centro Editor de América Latina.

Traducción de Josefina Delgado.

Genette, Gérard (1966). «Silences de Flaubert». Figures I. París: Éditions du Seuil.

Ritvo, Juan (1999). Formas de la sensibilidad. Restos de la cultura. Rosario: Laborde/Ross. 